\title{
Undergraduate physiotherapy students' knowledge of Diabetes Mellitus: Implications for education
}

\begin{abstract}
Diabetes mellitus is a growing public health concern and its prevalence is escalating exponentially, with a high frequency of morbidity, premature mortality, disability and loss of productivity. Since health education has become an important part of medical care physiotherapy students are potentially well suited to assist with the combat of this disease. The study

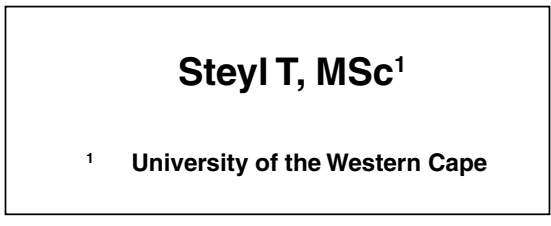
aimed to determine the knowledge of diabetes mellitus and its risk factors of undergraduate physiotherapy students in the Western Cape. The study incorporated a quantitative, cross-sectional design. Three hundred and thirty eight (338) students completed the structured, self-administered questionnaire consisting of three sections, namely socio-demographic information, diabetes mellitus risk factors and the validated 24-item Diabetes Knowledge Questionnaire (DKQ-24). Both descriptive and inferential statistics were employed and the alpha level was set at $p<0.05$. Overall, $60.7 \%$ of the study sample had adequate knowledge of diabetes mellitus ( $\geq 75 \%$ correct answers), while $32.5 \%$ and $6.8 \%$ had marginal ( $\geq 60 \leq 74 \%$ correct answers) and inadequate knowledge ( $<59 \%$ correct answers) respectively. Seven of the nine diabetes mellitus risk factors could readily be identified by $89.7 \%$ of the participants. Smoking (64.8\%) and high blood pressure (69.0\%) were not readily identified as common diabetes mellitus risk factors. Significant associations with diabetes risk factors were found for gender and year of study. The study has reinforced the need for continuous education of physiotherapy students regarding diabetes mellitus and its risk factors, as inadequate knowledge of diabetes mellitus could influence the effectiveness of patient education and therefore have dangerous consequences for the patient diagnosed with diabetes mellitus.
\end{abstract}

\section{KEY WORDS: DIABETES MELLITUS, RISK FACTORS, KNOWLEDGE, PHYSIOTHERAPY STUDENTS}

\section{BACKGROUND}

Diabetes mellitus, an international pandemic, is a growing public health concern and its prevalence is escalating exponentially, with a high frequency of morbidity, premature mortality, disability and loss of productivity (Steyn 2007) and high health care costs (Levitt et al 1999). The disease affected approximately 170 million individuals worldwide in the year 2000 and is estimated to be 366 million by the year 2030 (Wild et al 2004). Among these affected people, almost $85 \%$ burden is in developing countries (Nguma 2010). Although communicable diseases still contributes the most to disease burden, Murray and Lopez (1997) reported that by 2020 non-communicable diseases (NCDs), including hypertension and diabetes, will surpass communicable disease as a cause of death. This coincides with findings from the Western Cape Burden of Disease Report (2007) which stated that chronic diseases of lifestyle are the major cause of death in the Western Province.
South Africa has been noted to be undergoing a process of rapid epidemiological transition in terms of patterns of health and disease (Steyn et al 2000). The prevalence of diabetes mellitus in South Africa has increased drastically over the years (Somers et al 2006) due to population growth, ageing, urbanization, and an increase in prevalence of obesity and physical inactivity (Wild et al 2004). It has been estimated that approximately 1.5 million South African's are suffering from diabetes mellitus, a disease that ranks third in South Africa in terms of mortality and morbidity for the general population (Steyn 2007).

Moodley and Rambiritch (2007) state that the greatest weapon in the fight against diabetes mellitus is knowledge. Health education has become an important part of medical care. Health care professionals such as physiotherapists have an important role to play in increasing awareness of diabetes mellitus, disease prevention and health promotion. Physiotherapists are in an inimitable position to educate patients regarding the prevention of risk factors such as obesity and physical inactivity (Anthony et al 2004) as well as improving the functional ability of patients with diabetes mellitus and lessen the chances of physical impairments (Ozdirenc et al 2004). Various studies conducted among general practitioners, medical students and nurses showed inadequate knowledge of diabetes mellitus (Holstein, Widjaja, Nahrwold \& Egberts 2000; Hesset, Moran \& Boulton 1989) as well as inadequate skills for education and treatment of patients with diabetes (Talat, Nabeel \& Naueen 2003; Shera, Jawad \& Basit 2002). No

\section{Corresponding author:}

Tania Steyl

Department of Physiotherapy

Private Bag x17

Bellville

7535

Email: tsteyl@uwc.ac.za 
studies regarding physiotherapy students' knowledge of diabetes mellitus has been conducted in South Africa. While chronic diseases of lifestyle are a major challenge for health care professionals in the Western Cape, it is imperative that higher education training institutions are linking the knowledge of students to the needs of the community. Therefore, the overall aim of this study was to establish undergraduate physiotherapy students' knowledge of diabetes mellitus and its risk factors at three (3) universities in the Western Cape, South Africa.

\section{METHODS}

Ethical clearance and permission were obtained from the relevant authorities. The study employed a cross-sectional, quantitative design. The population included 619 undergraduate physiotherapy students registered for the 2009 academic year at three universities in the Western Cape, South Africa. All students were invited to participate in the study. Data collection was during June/July 2009 in either a class setting or not. The participation rate of less than $55 \%$ could be attributable to the nature of two of the universities' curriculum, as specific time for completion of the questionnaire in a class setting could not be done as a result of some of the students being on holiday and others on clinical placements.

The purpose of the study was clearly explained to the participants at the beginning of each session. Questionnaires for the other two participating universities were left with the specific class coordinators. Students were contacted by the class coordinator and asked to complete the questionnaire after the purpose of the study was explained to them. Each participant received an information sheet explaining their voluntary participation, confidentiality of information obtained as well as their right to withdraw from the study at any time with no impunity. Signed, informed consent was obtained from each participant.

Data were collected by means of a structured, self-administered questionnaire consisting of three (3) sections. Section one requested socio-demo- graphic information such as gender, age, institution, year of study, study year during which diabetes mellitus is taught at the university, family history of diabetes mellitus, diagnosed with diabetes mellitus and race/ethnicity (included for statistical purposes). Self-description was used for ethnicity classification. The self-constructed section two consisted of true or false responses to nine (9) diabetes mellitus risk factors. Section three consisted of the 24-item Diabetes Knowledge Questionnaire (DKQ-24), developed and validated by Garcia et al (2001). It has twenty-four (24) true and false statements relating to diabetes mellitus knowledge and has been used in several international studies (Chilton, $\mathrm{Hu} \&$ Wallace 2006; Mauldon, Melkus \& Cagganello 2006). The DKQ-24 has demonstrated internal consistency with a reliability coefficient of 0.78 . The questionnaire was piloted on ten (10) physiotherapy students to assess face validity and applicability of all the items for this population as well as the time it took to be completed. Only a few grammatical changes were made to section 1 and 2 before the final questionnaire was administered to the study sample.

Data obtained from the questionnaires were analyzed using the Statistical Package for the Social Sciences (SPSS) version 16.0. The data were subjected to both descriptive and inferential statistics. Demographic data were expressed as percentages, means and standard deviations. Data analysis included cross-tabulations using the Chi-square test for association between socio-demographic and specific variables (knowledge of diabetes mellitus and its risk factors). The alpha level was set at $\mathrm{p}<0.05$.

\section{RESULTS}

Three hundred and fifty one (351) participants completed and returned the questionnaires. Only those questionnaires $(n=338)$ with fully completed sections 2 (diabetes mellitus risk factors) and sections 3 (DKQ-24) were included in the data analysis. Therefore thirteen (13) questionnaires were excluded.
Thus the final response rate was $54.6 \%$ (338/691). The low response rate was a concern but other college studies have also obtained participation rates of approximately $50 \%$, so the present response rate is not out of line (Reifman \& Watson 2003). The final sample consisted of $82.0 \%(n=277)$ females and $18 \%(n=61)$ males with a mean age of 20.80 years $(\mathrm{SD}=2.02)$. The university representations were relatively equal in participation with $30.2 \%$ from University A, 32.5\% from University B and $37.3 \%$ from University C. More than half of the students $(63.6 \%)$ reported that they did not have a family history of diabetes mellitus.

\section{KNOWLEDGE OF DIABETES MELLITUS}

The following criteria for knowledge categories were used: inadequate for $\leq 59 \%$, marginal $\geq 60-75 \%$ was and adequate for $\geq 76 \%$ correct answers (Williams et al 1998). Overall, $60.7 \%$ of the study sample had adequate knowledge, $32.5 \%$ had marginal knowledge and $6.8 \%$ had inadequate knowledge of diabetes mellitus. Table 1 presents the responses to the 24-item Diabetes Knowledge Questionnaire (DKQ-24). Participants could select 'True' or 'False' for the different statements. The majority of the participants $(97.3 \%)$ knew that there are two main types of diabetes. Furthermore, $96.4 \%$ of the participants agreed that the usual cause of diabetes is lack of effective insulin in the body. More than two thirds $(66.9 \%)$ of the participants did not know that diabetic patients should cleanse a cut with iodine and alcohol and 60.9\% did not know that eating too much sugar and other sweet foods is not a cause of diabetes.

Seven of the 24-item DKQ questions had significant associations with the year of study, as illustrated in Table 2 . Significantly more of the $1^{\text {st }}$ year participants had incorrect responses to the abovementioned seven diabetes knowledge items. This concurs with the significant association found between categories of knowledge of diabetes mellitus and year of study as significantly more $1^{\text {st }}$ year students $\left(x^{2}=42.048\right.$, 
Table 1: Responses to the 24-item Diabetes Knowledge Questionnaire $(n=338)$

\begin{tabular}{|c|c|c|}
\hline Questions & Correct (\%) & Incorrect (\%) \\
\hline Eating too much sugar and other sweet foods is a cause of diabetes. (False) & 39.1 & 60.9 \\
\hline The usual cause of diabetes is lack of effective insulin in the body. (True) & 96.4 & 3.6 \\
\hline Diabetes is caused by failure of the kidneys to keep sugar out of the urine. (False) & 75.4 & 24.6 \\
\hline Kidneys produce insulin. (False) & 88.2 & 11.8 \\
\hline In untreated diabetes, the amount of sugar in the blood usually increases. (True) & 92.6 & 7.4 \\
\hline If I am diabetic, my children have a higher chance of being diabetic. (True) & 88.8 & 11.2 \\
\hline Diabetes can be cured. (False) & 88.5 & 11.5 \\
\hline A fasting blood sugar level of $11.5 \mathrm{mmol} / \mathrm{l}$ is too high. (True) & 85.2 & 14.8 \\
\hline The best way to check my diabetes is by testing my urine. (False) & 52.7 & 47.3 \\
\hline Regular exercise will increase the need for insulin or other diabetic medication. (False) & 75.7 & 24.3 \\
\hline $\begin{array}{l}\text { There are two main types of diabetes: Type } 1 \text { (insulin-dependent) and } \\
\text { Type } 2 \text { (non-insulin-dependent). (True) }\end{array}$ & 97.3 & 2.7 \\
\hline An insulin reaction is caused by too much food. (False) & 74.6 & 25.4 \\
\hline Medication is more important than diet and exercise to control diabetes. (False) & 83.1 & 16.9 \\
\hline Diabetes often causes poor circulation. (True) & 92.0 & 8.0 \\
\hline Cuts and abrasions on diabetics heal more slowly. (True) & 94.1 & 5.9 \\
\hline Diabetics should take extra care when cutting their toenails. (True) & 83.4 & 16.6 \\
\hline A person with diabetes should cleanse a cut with iodine and alcohol. (False) & 33.1 & 66.9 \\
\hline The way I prepare my food is as important as the foods I eat. (True) & 92.9 & 7.1 \\
\hline Diabetes can damage my kidneys. (True) & 84.9 & 15.1 \\
\hline Diabetes can cause loss of feeling in my hands, fingers, and feet. (True) & 87.3 & 12.7 \\
\hline Shaking and sweating are signs of high blood sugar. (True) & 71.3 & 28.7 \\
\hline Frequent urination and thirst are signs of low blood sugar. (False) & 43.8 & 56.2 \\
\hline Tight elastic hose or socks are not bad for diabetics. (False) & 72.5 & 27.5 \\
\hline A diabetic diet consists mostly of special foods. (False) & 47.9 & 52.1 \\
\hline
\end{tabular}

$\mathrm{p}=0.000$ ) had inadequate knowledge of diabetes mellitus. This finding is not exceptional as all three universities only cover the diabetes topic in the $3^{\text {rd }}$ and $4^{\text {th }}$ year of their curriculum. Furthermore, significantly more participants from University A (14.7\%) than University B (1.8\%) and University C (4.8\%) had inadequate knowledge of diabetes mellitus ( $\mathrm{p}=0.002)$.

No significant association were found between knowledge of diabetes mellitus and having a family history of diabetes mellitus $(n=6)$ and being diagnosed with diabetes mellitus $(n=2)$ respectively.

\section{KNOWLEDGE OF DIABETES MELLITUS RISK FACTORS}

The majority of the students were able to identify obesity (95.6\%), unhealthy diet $(96.2 \%)$, impaired glucose levels $(93.8 \%)$, raised fasting blood glucose levels $(94.7 \%)$ and high cholesterol $(75.1 \%)$ as risk factors for diabetes mellitus. In contrast smoking $(64.8 \%)$ and high blood pressure $(69.0 \%)$ were not readily identified as common risk factors of diabetes mellitus, as illustrated in Table 3.

A significant difference was found between knowledge of risk factor items and gender, with females more likely to identify an unhealthy diet $\left(\mathrm{x}^{2}=10.981\right.$, $\mathrm{p}=0.027)$ and obesity $\left(\mathrm{x}^{2}=18.786\right.$, $\mathrm{p}=0.016$ ) as risk factors for diabetes mellitus. Furthermore, significantly more $1^{\text {st }}$ year students did not identify smoking $\left(\mathrm{x}^{2}=25.230, \mathrm{p}=0.000\right)$, while $2^{\text {nd }}$ year students did not identify increased blood pressure $\left(\mathrm{x}^{2}=20.310, \mathrm{p}=0.002\right)$ as risk factors for diabetes mellitus respectively. 
Table 2: Significant associations between year of study ( $1^{\text {st }}$ year) and knowledge of diabetes mellitus

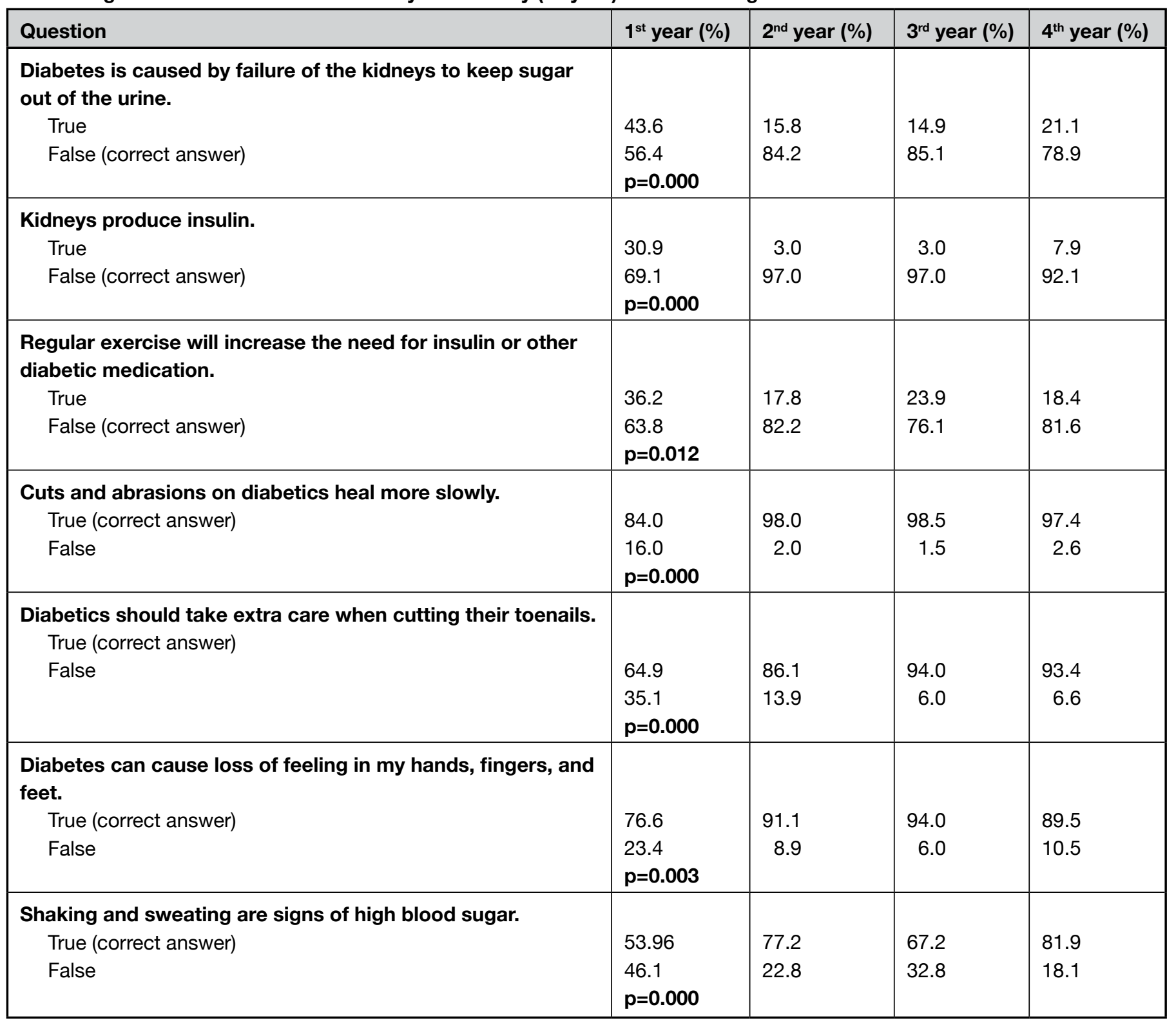

Table 3: Distribution of knowledge of DM risk factors

\begin{tabular}{|l|l|l|l|l|}
\hline Risk factor & \multicolumn{2}{|c|}{ Yes } & \multicolumn{2}{|c|}{ No } \\
\hline & $\mathbf{n}$ & $\%$ & $\mathbf{n}$ \\
\hline High cholesterol & 254 & 75.1 & 84 & 24.9 \\
\hline High fasting glucose levels & 295 & 87.3 & 43 & 12.7 \\
\hline Impaired glucose levels & 317 & 93.8 & 21 & 6.2 \\
\hline Raised blood glucose levels & 320 & 94.7 & 18 & 5.3 \\
\hline High blood pressure & 233 & 68.9 & 105 & $\mathbf{3 1 . 1}^{*}$ \\
\hline Smoking & 219 & 64.8 & 119 & $\mathbf{3 5 . 2}^{*}$ \\
\hline Physical inactivity & 289 & 85.5 & 49 & 14.5 \\
\hline Unhealthy diet & 325 & 96.2 & 13 & 3.8 \\
\hline Obesity & 323 & 95.6 & 15 & 4.4 \\
\hline
\end{tabular}

*not readily identified as a risk factor for diabetes mellitus 


\section{DISCUSSION}

It is estimated that $70 \%$ of patients with diabetes are living in developing countries (Ghazanfari, Ghofranpouri, Tavafian, Ahmadi \& Rajab 2007). Diabetes mellitus is currently ranked $5^{\text {th }}$ in the Western Cape Province, South Africa as cause of premature mortality (Western Cape Burden of Disease Reduction Project: Final Report 2007). Due to the projected increase in the prevalence of diabetes mellitus in the next twenty years, the importance of early detection and primary prevention cannot be stressed enough (Nisar et al 2008). The rising morbidity and mortality related to non-communicable diseases such as diabetes mellitus have major implications for the delivery of healthcare services. Increased awareness and knowledge of modifiable diabetes risk factors could be used to stem the present diabetic epidemic globally (Mayer-Davis 2008). Physiotherapists, as part of the multi-disciplinary team, are in many cases the first line practitioner and key source of information for patients suffering from diabetes mellitus (Garcia et al 2001). During their university training physiotherapy students are equipped with knowledge regarding prevention of diabetic complications by modification of risk factors such as obesity and physical inactivity, education on wound care as well as functional retraining after amputations (University of the Western Cape, $3^{\text {rd }}$ year Physiotherapy Curriculum).

Williams et al (1998) stated that patient education plays a key role in the prevention and control of the adverse health effects of CDLs such as diabetes mellitus with knowledge of risk factors as well as the nature of the disease remaining the most important goals of diabetes mellitus education programmes. This study highlights that physiotherapy students demonstrate average knowledge of diabetes mellitus and its risk factors with almost forty percent (39.3\%) of the participants having inadequate to marginal knowledge of diabetes mellitus. This could have a negative impact on the knowledge the students convey to their patients.
Acknowledgement of the risk factors of diabetes mellitus plays a pivotal role in its prevention. Rajaram (2007) states that the increased prevalence of diabetes mellitus in the South African population could be associated with risk factors being poorly monitored and prevented. It is of utmost importance that physiotherapy students should be able to identify well-known risk factors for diabetes mellitus in order to correctly inform their patients regarding the modifiable risk factors. The levels of knowledge of diabetes risk factors of the participants are promising as seven of the nine risk factors were readily identified by $89.7 \%$ of the participants. These results coincide with a study among medical students where $95 \%$ of the clinical students and $86 \%$ of the pre-clinical students have significant knowledge of the risk factors of diabetes mellitus (Mumtaz, Ashfaq \& Siddiqui 2009).

Prevention is always better than cure. The benefits of exercise in diabetes prevention and management has been proven in several studies (Gill \& Cooper 2008; Mayer-Davis 2008). The results of this study is promising as $83.1 \%$ of the students know about the key role physical activity plays in the prevention of diabetes and its complications.

The divergence in knowledge of diabetes mellitus between the participating universities can be due to the difference in the content of the module as well as teaching styles (didactic vs problembased learning). The current curricula of the participating universities focus mainly on individual patient and disease management, aiming at preventing disease deterioration of the condition. Due to the rapid increase of diabetes mellitus cases globally, it will be impossible to manage all those affected with diabetes mellitus individually (Hjelm, Mufunda, Nambozi \& Kemp, 2003). This means that measures have to be directed against the development of the disease, thus focusing on the healthy person. Preventive activities must be aimed at the entire society via community intervention programmes, and need to be integrated with measures directed against other diseases such as hypertension and cardiovascular disease. Therefore the universities should move away from the 'individual disease management approach' to a populationbased approach.

\section{LIMITATIONS AND RECOMMENDATIONS OF THE STUDY}

The findings are relevant to students of the three universities in the Western Cape only and cannot be generalized to students of other South African universities. However, the present findings lay the groundwork for similar studies amongst health science university students. Lastly, casual deductions cannot be made about the results gained as the study utilized a cross-sectional study design.

\section{CONCLUSION}

Knowledge of diabetes mellitus and its risk factors are essential for primary healthcare in order to prevent co-morbidities that can increase the burden of the disease. Although the results of the study revealed that almost $60 \%$ of the undergraduate physiotherapy students in the Western Cape have adequate knowledge of diabetes mellitus, some areas are still lacking. The lack of basic knowledge could influence the effectiveness of patient education and therefore have dangerous consequences for the patient diagnosed with diabetes mellitus. The physiotherapy curricula should include a sound knowledge base about diabetes mellitus and its management, as well as population-based health promotion programmes for patients with diabetes (prevention of possible complications) and health promotion activities to raise awareness among healthy people (prevention of the disease).

\section{ACKNOWLEDGEMENT}

I would like to thank the following $4^{\text {th }}$ year students who assisted with data collection: Melanie Kemp, Mariam Gani, Shavani Naicker, Shuaib Rasool and Danielle Roux. 


\section{REFERENCES}

Anthony S, Kelly K, Odgers T 2004 Health promotion and health education about diabetes mellitus. The Journal of the Royal Society for the Promotion of Health 124:70-73

Chilton L, Hu J, Wallace DC 2006 Healthpromoting lifestyle and diabetes knowledge in Hispanic American adults. Home Health Care Management and Practice 18(5):375-385

Garcia AA, Kouzekanani KK, Villagomez ET, Hanis GL, Brown SA 2001 The Starr County diabetes education study: development of the Spanish-language diabetes questionnaire. Diabetes Care 24:16-21

Ghazanfari Z, Ghofranpouri F, Tavafian SS, Ahmadi F, Rajab A 2007 Lifestyle education and diabetes mellitus type 2: a non-randomized control trial. Iranian Journal of Public Health 36:68-72

Gill JMR, Cooper AR 2008 Physical activity and prevention of Type 2 diabetes mellitus. Sports Medicine 38(10): 807-824

Hesset C, Moran A, Boulton AJ 1989 An evaluation of diabetic knowledge among general practitioners and senior medical students. Central Manchester health authority working party on diabetic care. Diabetic Medicine 6:351-353

Hjelm K, Mufunda E, Nambozi G, Kemp J 2003 Preparing nurses to face the pandemic of diabetes mellitus: a literature review. Journal of Advance Nursing 41(5):424-434

Holstein A, Widjaja A, Nahrwold D, Egberts EH 2000 Clinically relevant diabetes knowledge and experience among final year medical students. Practical Diabetes International 17:3-8

Levitt NS, Steyn K, Lambert EV, Reagon G, Lombard CJ, Fourie JM, Rossouw K, Hoffman M 1999 Modifiable risk factors for type 2 diabetes mellitus in a peri-urban community in South Africa. Diabetic Medicine 16:946-950

Mauldon M, Melkus GD, Cagganello M 2006 A culturally appropriate diabetes education program for Spanish-speaking individuals with type 2 diabetes mellitus - evaluation of a pilot project. The Diabetes Educator 32(5):751-760

Mayer-Davis EJ 2008 Type 2 diabetes in youth: epidemiology and current research toward prevention and treatment. Journal of American Dietetic Association 108:45-51
Myers J, Naledi T (2007). Western Cape Burden of Disease Reduction Project: Volume 1 of 7 : Overview of the Final Report 2007. Available at: www.capegateway.gov.za

Moodley LM, Rambiritch V 2007 An assessment of the level of knowledge about diabetes mellitus among diabetic patients in a primary healthcare setting. South African Family Practice 49:10

Mumtaz S, Ashfaq T, Siddiqui H 2009 Knowledge of medical students regarding diabetes mellitus at Ziauddin Unversity, Karachi. Journal Pakistan Medical Association 59:163-166.

Murray CJL, Lopez AD 1997 Mortality by cause of eight regions of the world: Global Burden of Disease Study. Lancet 349:1269-1276

Nguma LK 2010 Health seeking and health related behaviour for type 2 diabetes mellitus among adults in an urban community in Tanzania. Unpublished $\mathrm{PhD}$ thesis

Nisar N, Khan IA, Quadri MH, Sher SA 2008 Knowledge and risk assessment of diabetes mellitus at primary care level: a preventive approach required combating the disease in a developing country. Pakistan Journal of Medical Sciences 24:667-672

Ozdirenc M, Kocak GS, Guntekin R 2004 The acute effects of in-patient physiotherapy program on functional capacity in type 2 diabetes mellitus. Diabetes and Clinical Practice 64:167-172.

Rajaram, SK 2007 The status of the world diabetes dilemma: South African Perspectives. Retrieved February 14, 2009, from http://web.wits.ac.za/ NewsRoom/NewsItems/WorldDiabetesDilemma. htm

Reifman A, Watson WK 2003 Binge drinking during the first semester of college: continuation and desistance from high school. Journal of American College Health 52:73-78

Shera AS, Jawad F, Basit A 2002 Diabetes related knowledge, attitude and practices of family physicians in Pakistan. Journal Pakistan Medical Association 52:465-470

Somers A, Rusford E, Hassan MS, Erasmus RT 2006 Screening for diabetes mellitus in learners residing in the Belhar, Delft and Mfuleni communities of Cape Town, Western Cape, South Africa. South African Family Practice 48:16a-d

Steyn K 2007 The Heart and Stroke Foundation South Africa: Heart disease in South Africa. Media Data Document Department of Medicine, University of Cape Town \& Chronic Diseases of Lifestyle Unit, at the Medical Research Council.
Steyn NP, Senekal M, Brits S, Nel J 2000 Urban and rural differences in dietary intake, weight status and nutrition knowledge of black female students. Asia Pacific Journal of Clinical Nutrition 9: 53-59

Talat N, Nabeel A, Nauneen A 2003 Is there need of specialized diabetes nurses in Pakistan? Pakistan Journal of Medical Science 19:75-79

Western Cape Burden of Disease Reduction Project: Final Report (2007). Volume 2: Mortality Surveillance. Retrieved June 7, 2011, from www.capegateway.gov.za

Wild S, Roglic G, Green A, Sicree R, King H 2004 Global prevalence of diabetes: estimates for the year 2000 and projections for 2030. Diabetes Care 27:1047-1053

Williams MV, Baker DW, Parker RM, Nurss JR 1998 Relationship of functional health literacy to patients' knowledge of their chronic disease Archieves of Internal Medicine 158:166-172 